\title{
Delayed Diagnosis of Kartagener Syndrome in a Fertile Young Man - An Unusual Case
}

\author{
Fatima Alhamed Alduihi \\ Department of Internal Medicine, Aleppo University Hospital, Aleppo, Syria
}

$\mathrm{P}$ rimary ciliary dyskinesia (PCD) is an autosomal recessive disease characterised by dysfunction of ciliary motility associated with impaired mucociliary clearance. Kartagener syndrome, by definition, is a triad of situs inversus, bronchiectasis and chronic sinusitis, and is a subdivision of PCD. It can cause abnormal sperm motility and infertility in men, and can also cause infertility in women because of impaired cilia motility in fallopian tubes. In this case report, a 31-year-old male, non-smoker, born to non-consanguineous parents, presented to the emergency department with severe breathlessness and chest pain. He had a bad cough with yellow sputum. High-resolution computerised tomography showed bronchiectasis, and ultrasonography showed dextrocardia without situs inversus. He was treated with imipenem and amikacin according to sputum culture for 2 weeks, and then he was discharged on inhaled tobramycin. The distinctive aspect of this case, is that not only was this the first time this patient had been diagnosed with Kartagener syndrome, but he is also fertile (he had fathered two children), which is considered rare, but not impossible, in such cases. Fertility, as this case shows, does not therefore exclude Kartagener syndrome, and clinicians must suspect it in every case of dextrocardia, chronic sinusitis and bronchiectasis, because misleading the diagnosis can developed poor prognosis.

\section{Keywords}

Kartagener syndrome, situs inversus, fertility, primary ciliary dyskinesia

Disclosure: Fatima Alhamed Alduihi has nothing to declare in relation to this article. Acknowledgment: The author would like to acknowledge the help rendered by Dr Abdullah Khoury, Professor of Internal Medicine and Consultant in Pulmonary Medicine in Aleppo University Hospital for his constant encouragement and support in preparation of this manuscript. Review Process: Double-blind peer review.

Compliance with Ethics: All procedures were followed in accordance with the responsible committee on human experimentation and with the Helsinki Declaration of 1975 and subsequent revisions. A written consent form has been obtained from the patient and he gives his consent for his images and other clinical information to be reported in the journal.

Authorship: The named author meets the International Committee of Medical Journal Editors (ICMJE) criteria for authorship of this manuscript, takes responsibility for the integrity of the work as a whole, and has given final approval for the version to be published.

Received: 20 October 2019

Accepted: 5 November 2019

Citation: European Respiratory \&

Pulmonary Diseases. 2019;5(1):25-7

Corresponding Author: Fatima Alhamed Alduihi, Department of Internal Medicine, Aleppo University, Aleppo, Syria. E: dr.duihi88@hotmail.com; ORCiD: https://orcid.org/0000-0003-1083-9005; Twitter: @FatimaDuihi

Support: No funding was received in the publication of this article.
Primary ciliary dyskinesia (PCD) is an autosomal recessive disease characterised by dysfunction of ciliary motility associated with impaired mucociliary clearance. ' Kartagener syndrome is characterised by the triad of: sinusitis, bronchiectasis and situs inversus. ${ }^{2,3}$ Situs inversus is a condition whereby the visceral organs are completely, or partially, arranged in a mirror-image reversal of their normal positions. ${ }^{7}$ The percentage of patients with PCD that exhibit situs inversus varies, but in general, it is around $50-70 \%{ }^{4-6}$ Infertility is common in men with Kartagener because of impairment of sperm motility.

\section{Case presentation}

A 31-year-old male, non-smoker, born to non-consanguineous parents, presented to the emergency department with severe breathlessness and chest pain. He had a bad cough with yellow sputum for 7 days prior. He was treated with cephalosporins without any benefit. He also reported episodes of headache and recurrent cough, which had been persistent for up to 1 year. The patient married 12 years ago and has two children. The first was born 8 years ago (after 4 years of marriage), and the second 5 years ago. He has had no further children.

Upon examination, the patient displayed reflexes of a conscious and oriented person His blood pressure was $110 / 70 \mathrm{mmHg}$, heart rate was 108 beats/minute, and respiratory rate was 22 breaths/minute. Oximetry on admission was $84 \%$ and temperature was $38^{\circ} \mathrm{C}$. The patient had a cough with purulent sputum but no haemoptysis. Clubbing was seen in both hands (Figure 1). The patient also presented with auscultation of chest reflexes, wheezing and bilateral coarse crackles, which were heard more clearly on the right side. Auscultation of heart sounds revealed an apex beat heard on the right side.

Dyspnoea was the dominant symptom. No lymphadenopathy in two sides. Investigations carried out included complete blood count, haemoglobin $11.87 \mathrm{~g} / \mathrm{dl}$, white blood cell $8.5 \times 10^{\circ} / \mathrm{L}$; C-reactive protein $140.7 \mathrm{mg} / \mathrm{L}$; and serum amylase and lipase, which were normal. Chloride sweat test was $12 \mathrm{mEq} / \mathrm{L}$, which is within normal limits (Table 1). Pulmonary function tests revealed severe restriction (Table 2). Posterior anterior chest X-ray on admission showed dextrocardia (Figure 2). Simple sinusitis photo showed the patient had a deviated left nasal septum with sinusitis.

A computed tomography (CT) scan was then performed and revealed bronchiectasis (Figure 3), meaning the patient was at an increased risk of developing tuberculosis; therefore, we recommended that the patient attended the respiratory clinic for further follow-up. Unfortunately, even after treatment, the patient developed ground-glass opacity on $\mathrm{CT}$, and the lesion was doubled (Figure 4). 
Figure 1: Clubbing in both hands

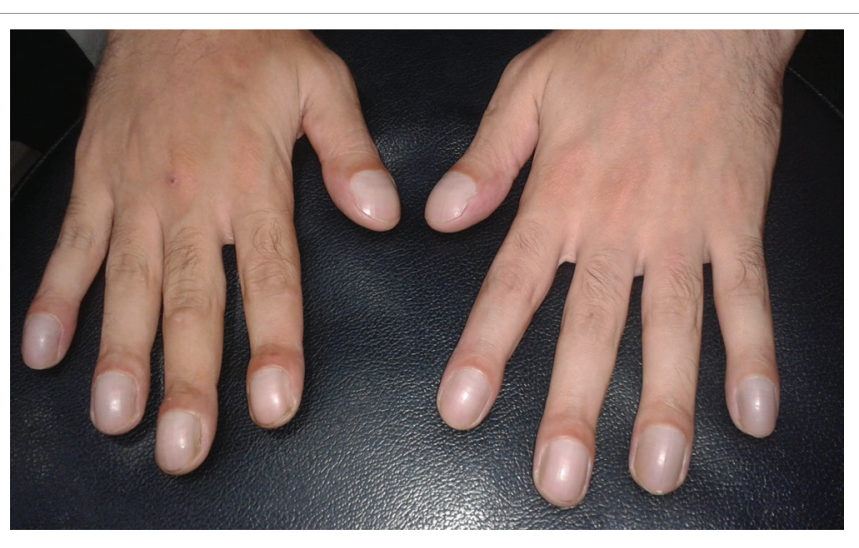

Table 1: Laboratory examinations

\begin{tabular}{|l|l|}
\hline White blood cells & $8.5 \times 10^{9} / \mathrm{L}$ \\
\hline Granulocytes & $73.6 \%$ \\
\hline Lymphocytes & $26.4 \%$ \\
\hline Haemoglobin & $11.87 \mathrm{~g} / \mathrm{dl}$ \\
\hline Hematocrit & $38 \%$ \\
\hline Platelets & $319 \times 10^{9} / \mathrm{L}$ \\
\hline Glucose (not fasting) & $155 \mathrm{mg} / \mathrm{dL}$ \\
\hline Urea & $12 \mathrm{mg} / \mathrm{dL}$ \\
\hline Alanine transaminase & $9 \mathrm{units} / \mathrm{L}$ \\
\hline C-reactive protein & $140.7 \mathrm{mg} / \mathrm{L}$ \\
\hline Chloride in sweat & $12 \mathrm{mEq} / \mathrm{L}$ \\
\hline Creatinine & $0.68 \mathrm{mg} / \mathrm{dL}$ \\
\hline Amylase & $60 \mathrm{U} / \mathrm{L}$ \\
\hline Lipase & $34 \mathrm{U} / \mathrm{L}$ \\
\hline
\end{tabular}

Ultrasonography was performed and showed no situs inversus totally. A semen analysis showed 75 million spermatozoa with 80\% motility; however, the patient mentioned that the count was only 9 million 3 months ago. Sputum for acid-fast bacilli (AFB) staining (three times) was negative for Mycobacterium tuberculosis. Sputum was positive for an isolate of Citrobacter spp., which was resistant to cefotaxime, lincomycin, rifampicin, gentamycin and nitrofurantoin. This could explain why the patient did not benefit from treatment with cephalosporin. The sputum culture was, however, sensitive to imipenem and amikacin. The patient was diagnosed with Kartagener syndrome and was treated with imipenem for 2 weeks. His clinical state improved and he was discharged with treatment with inhaled tobramycin (300 mg twice daily) in two cycles (28 days on/28 days off cycle), before re-evaluating response.

\section{Discussion}

The patient described in this case report presented to the emergency department with acute breathlessness and he reported episodes of headaches for up to 1 year. He was subsequently diagnosed with Kartagener syndrome. Bronchiectasis is common and is seen in about $25 \%$ of all cases in Kartagener syndrome patients, and it is associated with chronic sinusitis. ${ }^{8}$

Diagnostic procedures for PCD, which confirm the impaired cilia motility, depend on the biopsy of nasal mucosa and laparoscopic biopsies of tubal mucosa; these are complex and not available in Syria, so the diagnosis
Table 2: Pulmonary function test

\begin{tabular}{|c|c|c|c|c|c|}
\hline Parameter & $\begin{array}{l}\text { Unit of } \\
\text { measurement }\end{array}$ & Description & $\begin{array}{l}\text { Predicted } \\
\text { value }\end{array}$ & Test & $\begin{array}{l}\% \text { (of } \\
\text { predicted } \\
\text { value) }\end{array}$ \\
\hline Best FVC & I(btps) & $\begin{array}{l}\text { Best Forced } \\
\text { vital capacity }\end{array}$ & 4.08 & 1.84 & 45.1 \\
\hline FVC & I(btps) & $\begin{array}{l}\text { Forced vital } \\
\text { capacity }\end{array}$ & 4.08 & 1.84 & 45.1 \\
\hline FEV1 & I(btps) & FEV in 1 second & 3.55 & 1.29 & 36.3 \\
\hline PEF & I/second & $\begin{array}{l}\text { Peak expiratory } \\
\text { flow }\end{array}$ & 8.73 & 2.36 & 27.0 \\
\hline FEV6 & I(btps) & FEV in 6 second & 4.28 & 1.75 & 40.9 \\
\hline PIF & I/second & $\begin{array}{l}\text { Peak inspiratory } \\
\text { flow }\end{array}$ & & 1.36 & \\
\hline $\begin{array}{l}\text { FEV1/ } \\
\text { FVC \% }\end{array}$ & $\%$ & $\begin{array}{l}\text { FEV1 as \% of } \\
\text { FVC }\end{array}$ & 82.5 & 69.9 & 84.7 \\
\hline $\begin{array}{l}\text { FEV6/ } \\
\text { FVC \% }\end{array}$ & $\%$ & $\begin{array}{l}\text { FEV6 as \% of } \\
\text { FVC }\end{array}$ & & 95.1 & \\
\hline $\begin{array}{l}\text { FEV1/FEV } \\
6 \%\end{array}$ & $\%$ & $\begin{array}{l}\text { FEV1 as \% of } \\
\text { FEV6 }\end{array}$ & & 73.5 & \\
\hline $\begin{array}{l}\text { FEF } \\
25-75 \%\end{array}$ & I/second & $\begin{array}{l}\text { Forced mid- } \\
\text { expiratory flow }\end{array}$ & 4.65 & 0.93 & 20.0 \\
\hline MEF 75\% & I/second & MEF @ 25\% FVC & 7.40 & 1.92 & 25.9 \\
\hline MEF 50\% & I/second & MEF @ 50\% FVC & 4.83 & 1.23 & 25.5 \\
\hline MEF 25\% & I/second & MEF @ 75\% FVC & 2.11 & 0.39 & 18.5 \\
\hline FET 100\% & second & $\begin{array}{l}\text { Forced } \\
\text { expiratory time }\end{array}$ & & 6.4 & \\
\hline
\end{tabular}

$F C V=$ forced vital capacity; FEV = forced expiratory volume; FET = forced expiratory time; $M E F=$ mid-expiratory flow; PEF = peak expiratory flow; PIF = peak inspiratory flow.

of this case was clinically and supported by radiological images. The diagnosis of Kartagener syndrome is usually made in childhood; however, some cases are delayed to the third decade or later, especially in cases where the patient is fertile and asymptomatic. ${ }^{9,10}$ The patient described here had not previously been diagnosed with Kartagener, had never undergone high-resolution $\mathrm{CT}$.

As Kartagener syndrome is a form of $P C D$, the motility of cilia will be affected by this disease, and as a result, infertility is not uncommon in patients with PCD. About $50 \%$ of male patients with PCD are infertile due to lack of sperm motility. ${ }^{11}$ The patient in this case has two children and his semen analysis reported normal motility (45 million sperm with $80 \%$ motility). Though it is worth noting that most infertile patients with Kartagener syndrome have a normal spermatozoid count, but with a structural defect and a lack of motility, ${ }^{12}$ which is a result of the genetic causes linked to PCD. Disorders of cilia motility may be congenital or acquired. Up to $6.3 \%$ of patients with PCD have heterotaxy, and most of those have cardiovascular abnormalities, ${ }^{13}$ one such abnormality which was reported in our patient was dextrocardia. Patients with situs abnormalities have more ciliary outer dynein arm defects and fewer inner dynein arm defects, in addition to central apparatus defects and more mutations in ciliary outer dynein arm genes (DNA/1 and DNAH5). 14,15 To date, pathogenic variants in DNAH1, SEPT12, SLC26A8, CATSPER1, CATSPER2 and ADCY10 have been reported to cause non-syndromic asthenozoospermia, and DNA11,DNAH5, DNAAF2, CCDC39, DYC1X1 and $\angle R R C 6$ have been implicated in primary ciliary dyskinesia and syndromic asthenozoospermia. ${ }^{16}$ The case we have presented here supports the syndromic asthenozoospermia. 
Figure 2: Posterior anterior chest X-ray shows dextrocardia

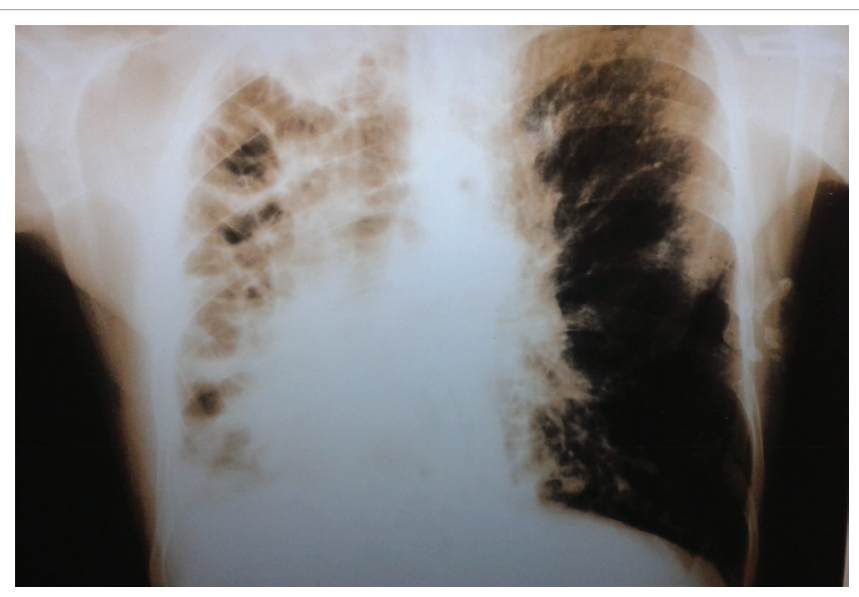

Figure 3: A computed tomography scan showing bronchiectasis

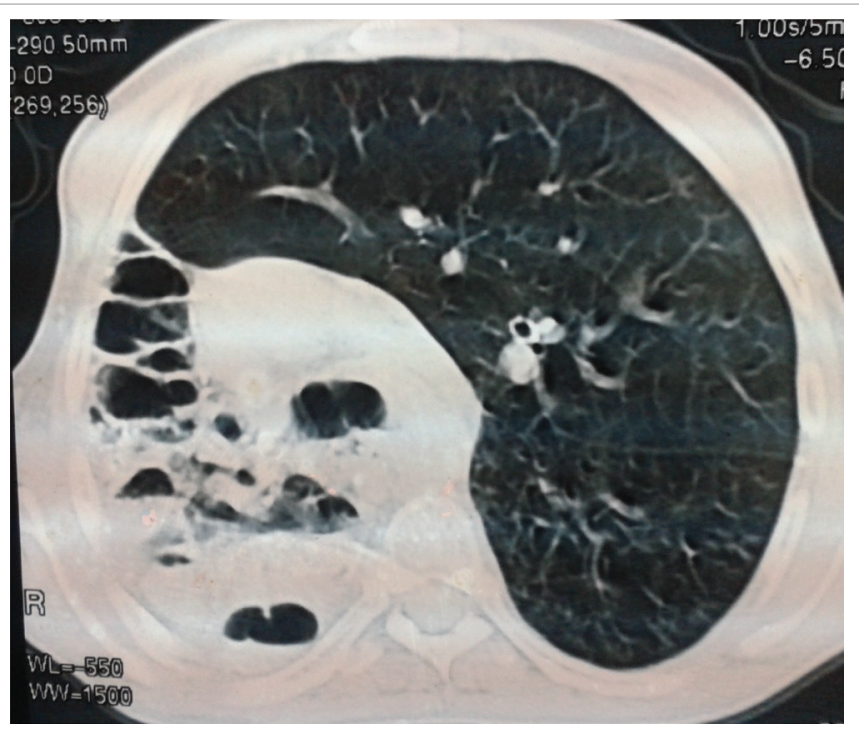

Infertility in male patients with Kartagener syndrome is due to the lake of sperm motility, while in females it is due to defective ovum transport because of dyskinetic motion of oviductal cilia. ${ }^{17}$ Prognosis in these patients is poor in general, even with treatment. The patient in our case will require comprehensive follow-up, as he is at increased risk of

\section{Figure 4: Computed tomography scan after treatment}

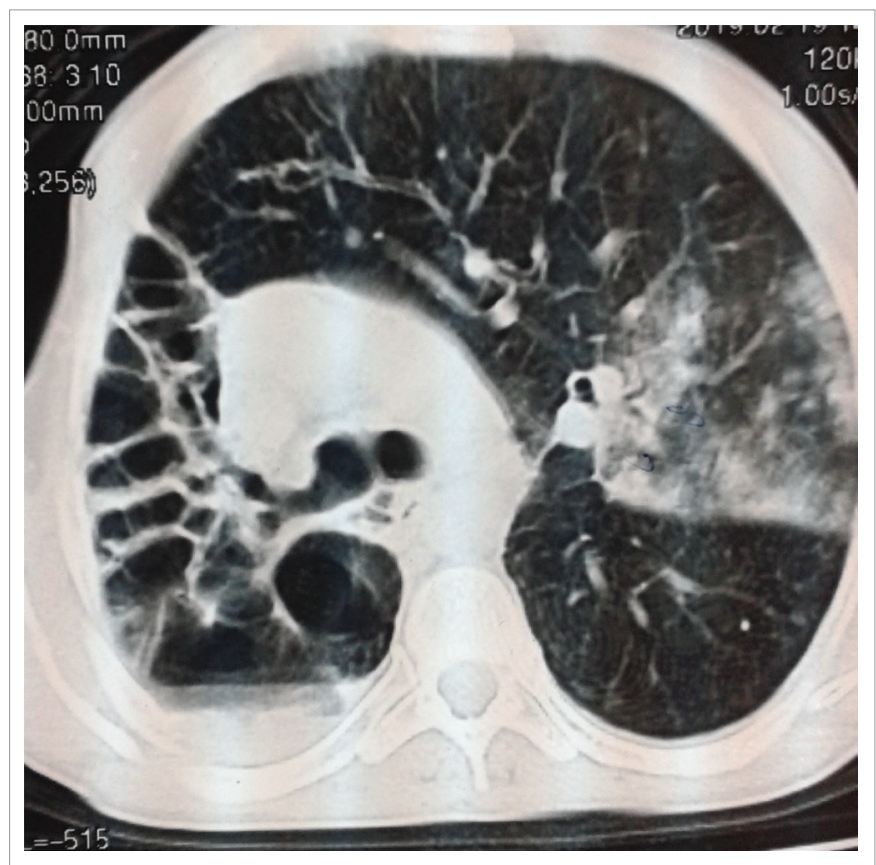

tuberculosis. Tuberculosis is common complication in patients with lower lobe bronchiectasis. ${ }^{18,19}$ Sputum AFB staining in the present case was negative for Mycobacterium tuberculosis; however, there remains a high risk of developing tuberculosis. At this stage, surgery would not improve this patient because bronchiectiasis is present in both lungs, and if surgery was chosen, both lungs would need to be transplanted, which is not possible in Syria, and recurrent infections should be controlled by antibiotics. ${ }^{20}$ There have been reports that support the use of sinus surgery in such patients, but this is an area where further investigation is required. ${ }^{21-23}$

\section{Conclusion}

Kartagener syndrome is a form of PCD that physicians should be aware of. It must be suspected in every patient presents with chronic sinusitis, bronchiectasis and dextrocardia, even if there is complete situs inversus or not. Infertility is common in such patients; however, the fertility of the patient in this case did not exclude the diagnosis of PCD. It is important to conduct a CT scan for every patient with dextrocardia. Finally, treatment of recurrent respiratory infections with antibiotics is the basis for controlling the disease, and surgery for sinusitis may be good last resort.

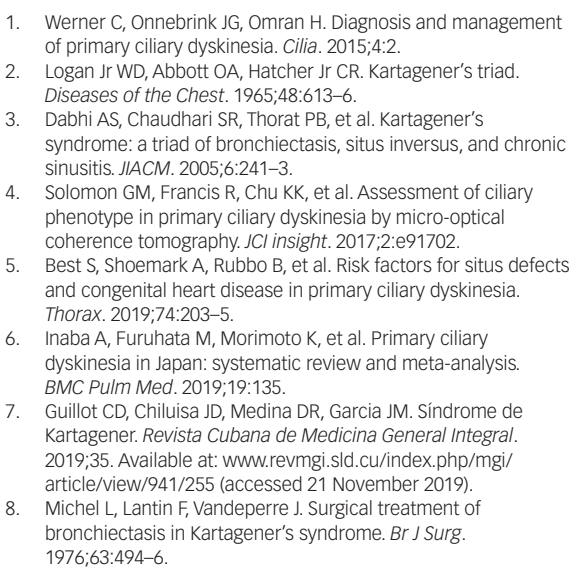

6. Inaba A, Furuhata M, Morimoto K, et al. Primary ciliary dyskinesia in Japan: systematic review and meta-analysis. BMC Pulm Med. 2019;19:135.

Guillot CD, Chiluisa JD, Medina DR, Garcia JM. Síndrome de Kartagener. Revista Cubana de Medicina General Integral. 2019;35. Available at: www.revmgi.sld.cu/index.php/mgi/ article/view/941/255 (accessed 21 November 2019).

8. Michel L, Lantin F, Vandeperre J. Surgical treatment of bronchiectasis in Kartagener's syndrome. Br I Surg. 1976;63:494-6.

Gómez FD, Gómez-Stern CA, Alvarez-Sala RW, et al. Kartagener's syndrome. Diagnosis in a 75 year-old woman. Archivos de bronconeumologia. 1999;35:242-4.

10. Barthwal MS. Kartagener's syndrome in a fertile male - An uncommon variant Lung India. 2006.23:123.

. Afzelius BA, Eliasson R. Male and female infertility problems in the immotile-cilia syndrome. Eur J Respir Dis Suppl. 1983:127:144-7.

12. Mohammed $\mathrm{M}$, Sundaramurthy $\mathrm{A}$, Ajeesh $\mathrm{K}$, et al. Situs inversus totalis with chronic respiratory ailment in a fertile male. JCDR. totalis with chronic resp

13. Shapiro AJ, Davis SD, Ferkol T, et al. Laterality defects other than situs inversus totalis in primary ciliary dyskinesia: insights into situs ambiguus and heterotaxy. Chest. 2014;146:1176-86.

14. Kennedy MP, Omran H, Leigh MW, et al. Clinical perspective Circulation. 2007;115:2814-21.

15. Hornef N, Olbrich H, Horvath J, et al. DNAH5 mutations are a common cause of primary ciliary dyskinesia with outer dynein arm defects. Am J Respir Crit Care Med. 2006;174:120-6

16. Akbari A, Anvar Z, Jaafarinia M, Totonchi M. Genetic etiology of Asthenozoospermia: a review. KAUMS Journal (FEYZ). 2019;23:318-33.
. McComb P, Langley L, Villalon M, Verdugo P. The oviductal cilia and Kartagener's syndrome. Fertil Steril. 1986:46:412-6.

18. Mitchell EB, Thornton Jr TF. Lower lobe bronchiectasis associated with tuberculosis. American Review of Tuberculosis. 1944; $49: 38-47$

19. Wang $S B$, Ye Q. Computerized tomography findings for missed diagnosis of pulmonary tuberculosis: analysis of 234 cases Int I Clin Exp Med. 2019:12:4168-73.

20. Nega B, Ademe Y, Tizazu A. Bronchiectasis: experience of surgical management at Tikur Anbessa Specialized Hospital, Addis Ababa, Ethiopia. Ethiop J Health Sci. 2019;29:471-6.

21. Gupta S, Handa KK, Kasliwal RR, Bajpai P. A case of Kartagener's syndrome: importance of early diagnosis and treatment. Indian J Hum Genet. 2013;19:266-9.

22. Wang $Y$, Yang HB. Effects of functional endoscopic sinus surgery on the treatment of bronchiectasis combined with chronic rhino-sinusitis. Acta oto-laryngologica. 2016;136: 860-3.

23. Tang $\mathrm{X}$, Zou J, Liu $\mathrm{S}$. Endoscopic sinus surgery for treatment of Kartagener syndrome: a case report. Balkan Med $\mathrm{J}$ 2013;2013:244-7. 